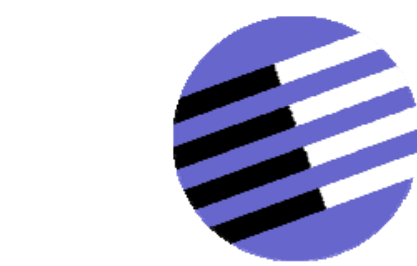

GOVERNANCE AND THE EFFICIENCY

OF ECONOMIC SYSTEMS

GESY

\begin{tabular}{|c|}
\hline Discussion Paper No. 169 \\
Haggling for Rents, \\
Relational Contracts, and the \\
Theory of the Firm \\
Oliver Gürtler*
\end{tabular}

October 2006

* Oliver Gürtler, Department of Economics, BWL II, University of Bonn, Adenauerallee 24-42, D-53113 Bonn, Germany. Tel.: +49-228-739214, Fax:+49-228-739210. oliver.guertler@uni-bonn.de

Financial support from the Deutsche Forschungsgemeinschaft through SFB/TR 15 is gratefully acknowledged. 


\title{
Haggling for Rents, Relational Contracts, and the Theory of the Firm*
}

\author{
Oliver Gürtler**, University of Bonn
}

\begin{abstract}
In this paper, a formal rent-seeking theory of the firm is developed. The main idea is that integration (compared to non-integration) facilitates rentseeking for the integrating party, but makes it harder for the integrated one. In a one-period model, this implies that the rent-seeking contest becomes more uneven and the parties rent-seek less. Here, integration is optimal. In the infinitely-repeated version of the model, it is also possible for the parties to enter a relational contract, under which each promises not to engage in rent-seeking. Such a contract must be self-enforcing, for it cannot be enforced by court. It is shown that integration makes the relational contract less easily sustainable, as, due to its cost advantage, the integrating party gains more from deviating than any party under non-integration. Hence, integration is preferred, if relational contracts are not sustainable, while, otherwise, nonintegration may well be preferred. Moreover, it is shown that the model's predictions are in line with many empirical facts on the choice of ownership structures.
\end{abstract}

Key words: Integration, non-integration, relational contracts, rent seeking JEL classification: D23, D72, D74, L14, L22

*I would like to thank Matthias Kräkel and Sanghack Lee for helpful comments. Financial support by the Deutsche Forschungsgemeinschaft (DFG), SFB-TR 15 (Governance and the efficiency of economic systems), is gratefully acknowledged.

** Oliver Gürtler, Department of Economics, BWL II, University of Bonn, Adenauerallee 24-42, D-53113 Bonn, Germany. Tel.:+49-228-739214, Fax:+49-228-739210; E-mail: oliver.guertler@uni-bonn.de 


\section{Introduction}

In a recent essay, Gibbons (2005) presents four different theories of the firm. One of these theories follows the idea by Williamson $(1971,1979,1985)$ and Klein et al. (1978) stating that integration (with conflict resolution by fiat) can stop inefficient haggling for appropriable quasi-rents (henceforth, called rent-seeking). While Gibbons agrees that such rent-seeking between firms is a leading cost of non-integration, he points to the large literature emphasizing that rent-seeking occurs within firms as well, i.e. that questions the effectiveness of fiat in resolving conflicts. ${ }^{1}$ In this sense, he convincingly argues that a comprehensive rent-seeking theory of the firm must endogenize the cost of integration in order to allow rent-seeking to occur within firms as well. Yet, he leaves the task of formalizing such a theory mainly for future research. $^{2}$

The aim of this paper is to fill this gap. In doing so, we face two further challenges. First and closely related to the endogenous determination of integration costs, we must show that integration can indeed be worse than non-integration in some instances. Second, the theory must be in line with empirical findings indicating that the likelihood of integration increases in the size of the appropriable rent. ${ }^{3}$

At the heart of our theory lies the question, how integration affects the parties' propensities to rent-seek. To answer this question, note that haggling for rents should cover all activities and, particularly, the elaboration of strategies that are aimed at forcing the other party to assign part of the rent.

\footnotetext{
${ }^{1}$ See, for example, the already mentioned paper by Klein et al. (1978) or the work by March (1962), Cyert \& March (1963) and Pfeffer (1981).

${ }^{2}$ In fact, Gibbons briefly presents a formal influence-cost theory of the firm. However, this theory does not simultaneously master the two challenges to be described in the next paragraph.

${ }^{3}$ See, for example, Monteverde \& Teece (1982) on ownership structures in the automobile industry, Masten (1984) on ownership structures in the aerospace industry, Anderson \& Schmittlein (1984) on firms' use of internal and external sales agents or Joskow (1985) on integration decisions of power companies.
} 
Such strategies are oftentimes based on threats in case the other party does not give in. Further, these threats should be more credible and, hence, the strategies more effective, the better the party's outside options. To give an example, suppose a party threatens to switch to a different trading partner unless the trading conditions are significantly altered in its favor. Then, this party is relatively likely to carry out its threat, if the consequences the switch in the trading partner entails are not too severe. Similarly, the party's initial trading partner is more likely to make concessions, the more it suffers from an end of the trading relationship. Hence, if one follows the property-rights theory of the firm (Grossman \& Hart, 1986; Hart \& Moore, 1990), which convincingly argues that a party's outside opportunities should improve in the number of assets the party possesses, a party possessing more assets should have a relative advantage in the rent-seeking process. We model this relative advantage by assuming the transfer of an asset within the relationship to make rent-seeking less costly for the new owner, but more costly for the initial owner. In the context of the integration/non-integration comparison, this means that integration makes rent-seeking more costly for the integrated party, but facilitates rent-seeking for the integrating one.

Applying these considerations to a one-period rent-seeking contest model, it can be shown that integration mitigates the rent-seeking problem under quite general conditions by making the contest more uneven. As the contest becomes less intense, each party decides to rent-seek less. Thus, if changes in the ownership structure are the only means to solve the rent-seeking problem, integration is optimal.

The one-period model yields similar results as the informal argumentations by Williamson and Klein et al.. Yet, it does not answer the question, why non-integration is, despite the existence of rent-seeking problems, oftentimes observed in practice. To find a satisfying answer, we extend the model by noting that integration is usually not the only instrument to mitigate the rent-seeking problem. Especially in long-lasting trading relationships, the parties may rely on reputational concerns to settle conflicts without engag- 
ing in costly rent-seeking activities, i.e. they may enter a relational contract forbidding the parties to engage in rent-seeking. ${ }^{4}$ Such a contract cannot be enforced by court and, hence, must be self-enforcing. Thus, to sustain a relational contract, the one-period gain of deviating and probably being awarded the rent at relatively low costs must be outweighed by the loss in terms of higher rent-seeking costs in future periods.

The analysis of the extended model focuses on how the chosen ownership structure affects the sustainability of relational contracts. It is shown that these contracts are less easily sustainable under integration than under nonintegration, which represents an important (and endogenously determined) cost of integration. This is due to our assumption that integration makes rent seeking less costly for the integrating party. Therefore, a deviation from the relational contract is more attractive for this party than for either party under non-integration. This implies that, for certain model parameters, relational contracts may be sustained under non-integration, but not under integration, in which case non-integration is strictly preferred.

To connect our model with the empirical result described before, we analyze, how the sustainability of relational contracts is affected by the size of the rent. We find two countervailing effects: First, a higher rent obviously increases the one-period gain of deviating from the relational contract. Second, the corresponding loss in future periods is usually higher, too, as, in the absence of relational contracts, rent-seeking increases in the size of the rent. In order to make more concrete predictions, we consider a specific example, in which the first effect is shown to be always dominant. Hence, in the example, relational contracts and, accordingly, non-integration are of particular relevance, if the appropriable rents are relatively small, while, for larger rents, these contracts are not sustainable and integration is preferred.

\footnotetext{
${ }^{4}$ One might wonder, why we stress the role of relational contracts, but neglect formal contracts in our analysis. This follows from the observation that appropriable quasi-rents usually exist, only if formal contracts are either incomplete or ineffective. Formal contracts may be implicitly incorporated in the size of the rent. The more detailed these contracts, the smaller should be the rent.
} 
Note that this is exactly in line with the empirical results indicating that, for small rents, non-integration is likely to be preferred, while, for larger rents, the opposite is true.

Besides to the literature mentioned so far, the paper is related to at least three other strands of economic literature. First, the paper is naturally related to the large literature on individual rent-seeking contests initiated by Tullock (1980) and further developed by e.g. Dixit (1987), Leininger (1993), Baik (1994), Konrad (2000), Lee (2000), Baye \& Hoppe (2003) or Morgan (2003). Second, the paper is closely related to a relatively small, but growing literature making contest models the core of a theory of the firm. Similar to our approach, Masten (1986) uses a contest model to formalize haggling between firms for appropriable quasi-rents. However, he simply assumes that integration eliminates all rent-seeking activities, but leads to fixed and exogenously given costs (which are independent of the size of the rent). As already argued at the beginning of this section, such an approach has different shortcomings, which we try to remove by endogenizing the costs of integration in our model. Müller \& Wärneryd (2001) show that outside ownership may mitigate rent-seeking within firms, as outsiders extract part of the rent so that insiders have less to fight about. Further, Konrad (2004) demonstrates that hierarchies, which are characterized by a sequence of rentseeking contests, may lead to lower total rent-seeking expenditures. ${ }^{5}$ Note that all these papers neglect relational contracts in their analysis. This is in stark contrast to the third strand of literature the paper is related to. The contributions by e.g. Garvey (1995), Baker et al. (2002) and Halonen (2002) emphasize the role of relational contracts for the choice of ownership structures. Different from the current paper, however, they neglect rentseeking considerations and focus on investment decisions. Therefore, they are more in the spirit of the property-rights theory of the firm.

The remainder of the paper is organized as follows: In the next section,

\footnotetext{
${ }^{5}$ Other papers that use contest models as main part of a theory of the firm include Ellingsen (1997) and Inderst et al. (2005, 2006).
} 
the model is presented and the stage game, in which relational contracts are not feasible, is solved. Section 3 considers the infinitely-repeated version of the stage game and contains the main results of the paper. A discussion of the model is offered in Section 4. Finally, Section 5 concludes.

\section{A one-period model of rent-seeking between and within firms}

\subsection{Description of the model and notation}

As mentioned in the introduction, we model haggling for appropriable quasirents as a rent-seeking contest. Consider a situation with two risk-neutral and unlimitedly liable parties, $i=1,2$, competing for a rent of size $R>0$. The probability that party 1 receives the rent is given by

$$
p\left(y_{1}, y_{2}\right)
$$

and depends on the total rent-seeking activities by both parties, $y_{1} \geq 0$ and $y_{2} \geq 0$, which lead to rent-seeking costs $C_{1}$ and $C_{2}$, respectively. Accordingly, $1-p\left(y_{1}, y_{2}\right)$ is the probability that party 2 wins the rent. We impose the following assumptions on $p$ :

Assumption 1: (i) $p$ is everywhere differentiable, (ii) $p$ is symmetric, i.e. $p\left(y_{1}, y_{2}\right)=1-p\left(y_{2}, y_{1}\right)$, (iii) $p_{1}>0, p_{11} \leq 0, p_{2}<0, p_{22} \geq 0,{ }^{6}$ (iv) $p_{12}>0 \Leftrightarrow p>0.5$.

Let me briefly discuss the intuitions and limitations behind the single assumptions. Concerning part (i) note that, in some applications, the function $p$ is assumed to be non-differentiable at $\left(y_{1}, y_{2}\right)=(0,0)$. This may well affect the results to be derived. Hence, in Section 4.1 we discuss the implications of having a contest-success function $p$, which is not everywhere differentiable.

\footnotetext{
${ }^{6}$ Here, as well as in all what follows, a subscript accompanying the function $p$ denotes a partial derivative.
} 
Part (ii) is a standard assumption as well as part (iii), which implies that rent-seeking has positive but (weakly) diminishing marginal effects on the own probability of winning the rent. Finally, part (iv) is very intuitive, too. If, initially, party 1 chooses higher rent-seeking, a marginal increase in $y_{2}$ makes it more attractive for party 1 to increase $y_{1}$ as well. This is due to the more intense competition the increase in party 2's rent-seeking activities has caused. Similarly, if, initially, $y_{1}<y_{2}$, an increase in $y_{2}$ makes the contest more uneven so that it is beneficial for party 1 to rent-seek less. Note that part (iv) together with Young's theorem implies that $p_{21}>0 \Leftrightarrow p>0.5$, which can be interpreted analogously. Notice further that part (iv) is fulfilled for the two most popular specifications of $p\left(y_{1}, y_{2}\right)$, the logit-form contestsuccess function $^{7}$ and the probit-form contest-success function ${ }^{8}$.

To obtain a theory of the firm, we must define what integration is compared to non-integration and explain, how the choice of ownership structure affects the model. As argued in the introduction, integration is assumed to facilitate rent-seeking for the integrating party, but makes it harder for the integrated one. To model this, we assume that there are two alienable (say, physical) assets, $a 1$ and $a 2$, that can be used for rent-seeking purposes. For instance, the party possessing a particular asset can threaten to withhold it to the other party unless being substantially better off. In this context, we introduce the functions $I_{1} \in\{0,1\}$ and $I_{2} \in\{0,1\}$ indicating whether party $1\left(I_{j}=1\right)$ or party $2\left(I_{j}=0\right)$ owns asset $a j, j=1$, Integration then means that both assets are allocated to a single party, while non-integration is achieved by giving each party exactly one of the assets. Let $d_{i j} \geq 0$ denote the amount of rent-seeking undertaken via asset $a j$ by party $i .^{9}$ This rent-seeking leads to costs $K\left(d_{i j}\right)$, where $K(\cdot)$ is supposed to be strictly increasing, strictly convex and satisfying $K(0)=0, K^{\prime}(0)=0$ and $K^{\prime}\left(d_{i j}\right)=\infty$

\footnotetext{
${ }^{7}$ For the logit-form contest see, for example, Tullock (1980). For a formal proof that part (iv) of Assumption 1 is fulfilled in both kinds of contest see Dixit (1987).

${ }^{8}$ See, e.g., Lazear \& Rosen (1981).

${ }^{9}$ Note that party $i$ can use the asset $a j$ for rent-seeking purposes only if it owns the asset.
} 
for $d_{i j} \rightarrow \infty .^{10}$

Further, suppose that there are two inalienable assets representing the human capital that belongs to each party. As in the case of alienable assets, a party may threaten to withhold its human capital so that human capital may be used for rent-seeking purposes as well. The variable $x_{i} \geq 0$ represents party $i$ 's amount of rent-seeking undertaken via inalienable asset and $C\left(x_{i}\right)$ the corresponding costs, with $C(\cdot)$ as an strictly increasing and strictly convex function satisfying $C(0)=0, C^{\prime}(0)=0, C^{\prime}\left(x_{i}\right)=\infty$ for $x_{i} \rightarrow \infty$. We assume that total rent-seeking by either party is simply the sum of rentseeking undertaken via alienable and inalienable assets. Together with the convexity of the cost functions, this implies that the integrating party can exert a certain amount of total rent-seeking at lower costs, making formally the assumption discussed in the introduction. ${ }^{11}$ Assumption 2 summarizes the foregoing arguments:

$$
\begin{aligned}
& \text { Assumption 2: (i) } y_{1}=x_{1}+\sum_{j} I_{j} d_{1 j}, \text { (ii) } y_{2}=x_{2}+\sum_{j}\left(1-I_{j}\right) d_{2 j}, \text { (iii) } \\
& C_{1}=C\left(x_{1}\right)+\sum_{j} I_{j} K\left(d_{1 j}\right), \text { (iv) } C_{2}=C\left(x_{2}\right)+\sum_{j}\left(1-I_{j}\right) K\left(d_{2 j}\right) .
\end{aligned}
$$

The timing of the model is as follows: At stage 1, the parties decide how to allocate the assets. As they are risk-neutral and unlimitedly liable, they choose the ownership structure minimizing total rent-seeking costs, $C_{1}+C_{2}$. At stage 2, they choose their rent-seeking activities. In this context, we assume that neither the size of the rent nor the amount of rent seeking undertaken (or, alternatively, the rent-seeking costs) are verifiable to a third party (e.g. a court). Consequently, the parties cannot write enforceable contracts to address the rent-seeking problem and we solve for a Nash-equilibrium of

\footnotetext{
${ }^{10}$ The last two conditions ensure the existence of an interior solution in the static model.

${ }^{11}$ Note that the cost advantage could also be modeled by canceling the explicit distinction between alienable and inalienable assets and assuming that total rent-seeking costs are given by $C_{i}\left(y_{i}, \theta_{i}\right)$, where $\theta_{i}$ depends on how many alienable assets party $i$ possesses. In this way, however, the decision to integrate could be driven by assumptions on how $\theta_{i}$ affects $C_{i}$. This dependence of ownership structures on assumptions about certain model parameters is avoided under the current model specification.
} 
the contest in a typical Cournot fashion. Finally, at stage 3, nature chooses a winner to the contest who is awarded the rent.

\subsection{Solution to the model}

We derive the solution for the case of non-integration and integration separately. Consider first the non-integration case, where each party possesses one alienable and one inalienable asset. Without loss of generality party 1 (2) is assumed to possess asset $a 1(a 2)$. The two parties' maximization problems are then given by

$$
\begin{aligned}
& \max _{x_{1}, d_{11}} p\left(x_{1}+d_{11}, x_{2}+d_{22}\right) R-C\left(x_{1}\right)-K\left(d_{11}\right), \\
& \max _{x_{2}, d_{22}}\left(1-p\left(x_{1}+d_{11}, x_{2}+d_{22}\right)\right) R-C\left(x_{2}\right)-K\left(d_{22}\right)
\end{aligned}
$$

The first-order conditions to the two maximization-problems are ${ }^{12}$

$$
\begin{aligned}
p_{1}\left(x_{1}^{*}+d_{11}^{*}, x_{2}^{*}+d_{22}^{*}\right) R-C^{\prime}\left(x_{1}^{*}\right) & =0 \\
p_{1}\left(x_{1}^{*}+d_{11}^{*}, x_{2}^{*}+d_{22}^{*}\right) R-K^{\prime}\left(d_{11}^{*}\right) & =0 \\
-p_{2}\left(x_{1}^{*}+d_{11}^{*}, x_{2}^{*}+d_{22}^{*}\right) R-C^{\prime}\left(x_{2}^{*}\right) & =0 \\
-p_{2}\left(x_{1}^{*}+d_{11}^{*}, x_{2}^{*}+d_{22}^{*}\right) R-K^{\prime}\left(d_{22}^{*}\right) & =0
\end{aligned}
$$

Suppose that $x_{1}^{*}>x_{2}^{*}$. From this condition, it follows that $d_{11}^{*}>d_{22}^{*}$, $x_{1}^{*}+d_{11}^{*}=y_{1}^{*}>y_{2}^{*}=x_{2}^{*}+d_{22}^{*}$ and $p_{1}\left(y_{1}^{*}, y_{2}^{*}\right)>-p_{2}\left(y_{1}^{*}, y_{2}^{*}\right)$. Differentiating the symmetry assumption on the contest-success function $p, p\left(y_{1}, y_{2}\right)=$ $1-p\left(y_{2}, y_{1}\right)$, with respect to $y_{1}$ yields $p_{1}\left(y_{1}, y_{2}\right)=-p_{2}\left(y_{2}, y_{1}\right)$. Hence, $p_{1}\left(y_{1}^{*}, y_{2}^{*}\right)>-p_{2}\left(y_{1}^{*}, y_{2}^{*}\right)$ can be rewritten as $p_{1}\left(y_{1}^{*}, y_{2}^{*}\right)>p_{1}\left(y_{2}^{*}, y_{1}^{*}\right)$. It is then a very easy task to show that $p_{1}\left(y_{2}^{*}, y_{1}^{*}\right) \geq p_{1}\left(y_{1}^{*}, y_{1}^{*}\right)>p_{1}\left(y_{1}^{*}, y_{2}^{*}\right)$, where the first inequality follows from $p_{11} \leq 0$ and the second from $p_{12}>0$, for $p>0.5$. This contradicts the assumption $p_{1}\left(y_{1}^{*}, y_{2}^{*}\right)>p_{1}\left(y_{2}^{*}, y_{1}^{*}\right)$ and, hence, $x_{1}^{*}>x_{2}^{*}$. Similarly, one can show that $x_{1}^{*}<x_{2}^{*}$ is incompatible with conditions (4) to

\footnotetext{
${ }^{12}$ The second-order conditions are satisfied. Except for a specific example to be presented in Appendix B, for which a further parameter restriction is needed, the same holds for all maximization problems that follow.
} 
(7) so that the equilibrium is symmetric with $x_{1}^{*}=x_{2}^{*}=: x^{N}, d_{11}^{*}=d_{22}^{*}=: d^{N}$ and $x_{1}^{*}+d_{11}^{*}=x_{2}^{*}+d_{22}^{*}=: y^{N}$. Using this symmetry, the first-order conditions simplify to

$$
\begin{aligned}
& p_{1}\left(y^{N}, y^{N}\right) R-C^{\prime}\left(x^{N}\right)=0 \\
& p_{1}\left(y^{N}, y^{N}\right) R-K^{\prime}\left(d^{N}\right)=0
\end{aligned}
$$

Let us now turn to the case of integration. As both parties are symmetric, it does not matter for our results, whether party 1 or party 2 is the integrating party. Assume, therefore, that party 1 integrates and possesses both alienable assets in addition to its inalienable one. Then, party 1 maximizes

$$
p\left(x_{1}+d_{11}+d_{12}, x_{2}\right) R-C\left(x_{1}\right)-K\left(d_{11}\right)-K\left(d_{12}\right)
$$

while party 2 maximizes

$$
\left(1-p\left(x_{1}+d_{11}+d_{12}, x_{2}\right)\right) R-C\left(x_{2}\right)
$$

Denote by $x_{1}^{I}, x_{2}^{I}, d_{1}^{I}$ and $d_{2}^{I}$ the solution to these maximization problems. This solution is given by the first-order conditions

$$
\begin{aligned}
p_{1}\left(x_{1}^{I}+d_{1}^{I}+d_{2}^{I}, x_{2}^{I}\right) R-C^{\prime}\left(x_{1}^{I}\right) & =0 \\
p_{1}\left(x_{1}^{I}+d_{1}^{I}+d_{2}^{I}, x_{2}^{I}\right) R-K^{\prime}\left(d_{1}^{I}\right) & =0 \\
p_{1}\left(x_{1}^{I}+d_{1}^{I}+d_{2}^{I}, x_{2}^{I}\right) R-K^{\prime}\left(d_{2}^{I}\right) & =0 \\
-p_{2}\left(x_{1}^{I}+d_{1}^{I}+d_{2}^{I}, x_{2}^{I}\right) R-C^{\prime}\left(x_{2}^{I}\right) & =0
\end{aligned}
$$

First, note that integration does not eliminate rent seeking as assumed in much of the informal literature on the theory of the firm. The integrated party still tries to use its inalienable asset for rent-seeking purposes. ${ }^{13}$ Nevertheless, under quite general conditions integration alleviates the rent-seeking problem, as the following proposition shows.

\footnotetext{
${ }^{13}$ The result that rent-seeking efforts are strictly positive follows directly from our assumptions on the single cost functions. Note, however, that rent-seeking costs are also strictly positive. This can be seen by inspection of the first-order conditions. As $p_{1},-p_{2}$ and $R$ are strictly positive, respectively, $C^{\prime}$ and $K^{\prime}$ must, at the optimum, be strictly positive, too. The latter observation implies that rent-seeking costs are strictly positive in equilibrium.
} 
Proposition 1 If $-p_{11}$ and $p_{22}$ are not too large, total rent-seeking costs are strictly higher under non-integration than under integration. Then, the parties always decide to integrate.

\section{Proof. See Appendix A.}

Proposition 1 states that integration mitigates the rent-seeking problem and is therefore preferred, if other instruments to address this problem are not available. The main advantage of integration is that it makes the rentseeking contest uneven and, accordingly, less intense. ${ }^{14}$ As a consequence, the integrating party's rent-seeking efforts are always lower than the corresponding efforts under non-integration. On the other hand, whether the integrated party's rent-seeking effort is also lower, is determined by a tradeoff of two countervailing effects. Next to the already mentioned "competition effect", there is a second effect due to the diminishing marginal returns of rent seeking. This second effect follows from the result that the integrated party's total rent seeking decreases, as it cannot use any alienable asset for rent-seeking purposes. Since $p_{22} \geq 0$, this may make it more attractive for this party to use the inalienable asset in the rent-seeking contest. Hence, even if $y_{2}^{I}<y^{N}$, it might be that $x_{2}^{I}>x^{N}$. In this case, it would be impossible to say whether integration or non-integration leads to higher total rent-seeking costs, although integration is probably still optimal. To rank the ownership structures unambiguously, we limit the positive effect on $x_{2}^{I}$ by imposing the restriction on $p_{22}$. A similar restriction on $p_{11}$ must be imposed, if party 2 is the integrating party. Note, however, that these restrictions are sufficient conditions that are usually excessively strong. Further, we suppose for the remainder of the paper that the restrictions do indeed hold so that integration is always selected in the static model.

Before turning to the multi-period model, it is interesting to compare integration as the so far proposed solution to the rent-seeking problem with

\footnotetext{
${ }^{14}$ Note that it has been shown before that more uneven contests may lead to lower rent dissipation. See, for example, Baik (1994). However, this has always been done under quite restrictive assumptions on the contest-success function $p(\cdot)$.
} 
another solution proposed in the economic literature, namely strategic delegation. As shown by Wärneryd (2000), strategic delegation may mitigate the rent-seeking problem, if delegates are limitedly liable. Under limited liability, they are given weaker incentives as the original contestants would face and so rent-seek less. In contrast to integration, however, strategic delegation is vulnerable to secret renegotiation. In particular, given the delegation equilibrium, the original contestant would have an incentive to pay the delegate his expected payoff from taking part in the contest and secretly engage in rent-seeking himself. This problem is avoided under integration, i.e. under integration there is no scope for secret renegotiation. Therefore, integration is a more robust commitment device than strategic delegation.

\section{A multi-period model of rent-seeking be- tween and within firms}

\subsection{Additional assumptions}

In this section, we consider the infinitely-repeated version of the stage game from the previous section. Our aim is to analyze the properties of relational contracts between the parties. To do so, some additional assumptions have to be introduced.

First, we assume that either party can observe, whether or not the other party has engaged in rent-seeking, i.e. party $i$ can observe, whether $y_{j}=0$ or $y_{j}>0, i \neq j$. This is a realistic assumption, as it is very difficult to find out the exact amount of rent seeking of the other party, while it is quite likely that one gets to know, whether the other party engaged in rent seeking at all.

Hence, the parties could enter a relational agreement, under which each promises not to engage in rent seeking. ${ }^{15}$ We assume that such a relational

\footnotetext{
${ }^{15}$ In principle, there are two kinds of relational contracts. In the first, both parties promise not to engage in rent seeking. In the second, only one party gives this promise,
} 
agreement is sustained by Grim-Trigger strategies. That is, each party starts by cooperating (i.e. by choosing $y_{i}=0$ ) and continues cooperation unless one party defects, in which case it refuses to cooperate forever after. Thus, if the relational agreement is reneged on once, the parties switch to the stagegame Nash-equilibrium derived in Section 2. ${ }^{16}$ In this context, we assume that renegotiation of the ownership structure is possible and may occur at zero cost. ${ }^{17}$ Therefore, after a breach of the relational contract, the parties always choose to integrate in order to save on rent-seeking expenditures.

Each party is assumed to discount future utility with a common factor $\delta \in(0,1)$. Alternatively, $\delta$ may describe the probability that the parties continue their relationship in the next period. Moreover, we assume that while the other party chooses a strictly positive level of rent seeking. Our main focus is on the former kind of contract. The latter is discussed in Section 4.2.

${ }^{16}$ These strategies are sometimes argued to be problematic, as they are not renegotiationproof. To see this, note that the game remaining after one party defects coincides with the game as a whole. As a consequence, equilibria being available in the game as a whole should also be available after the relational agreement was broken. Thus, the parties should be able to renegotiate from punishment to a different equilibrium with higher payoffs. This problem, however, can be easily solved (see e.g. the textbook by Bolton \& Dewatripont (2005), p. 467): Instead of playing the stage-game Nash equilibrium in the punishment phase, the parties could play jointly efficient punishments, but change the division of the surplus after a deviation. In particular, the division should be changed such that the deviating party receives exactly the same payoff as in the Nash-equilibrium of the stage game. Note that all results to be derived remain the same, if we assume the parties to follow this second type of strategy.

Further, if exactly one party deviates from the agreement, one might also think that the parties switch from the two-sided relational contract to a one-sided one, under which the party, which reneged on the contract, chooses a strictly positive level of rent seeking. The main results to be derived would also hold in this setting.

${ }^{17}$ The main result to be derived in this section is that non-integration may be beneficial, as it facilitates the sustainment of relational contracts. This result would even be enforced, if the ownership structure could not be renegotiated easily. In this case, non-integration had the additional effect that it leads to a higher punishment in case the relational agreement was broken. Then, the range of parameter values, for which a relational contract is sustainable under non-integration would further increase. 
each party has equal bargaining power. This is in line with our consideration of homogeneous parties.

\section{$3.2 \quad$ Two-sided relational contracts}

Under a two-sided relational contract, each party promises to choose $y_{i}=0$. If a party deviates optimally from this promise, it realizes a gain in the current period, as the benefit of being more likely to win the rent outweighs the additional rent-seeking costs. However, in future periods, it is worse off since it is no longer trusted.

We start by analyzing the one-period gain, if deviating from the agreement. The optimal deviation of party 1 depends on the chosen ownership structure and maximizes the subsequent expression,

$$
G=p\left(x_{1}+\sum_{j} I_{j} d_{1 j}, 0\right) R-C\left(x_{1}\right)-\sum_{j} I_{j} K\left(d_{1 j}\right)
$$

from which the following lemma can be derived:

Lemma 1 A party's one-period gain of deviating from the relational agreement is higher the more assets the party possesses and increasing in the size of the rent, $R$.

Proof. See Appendix A.

Lemma 1 is very intuitive. A party deviating from the relational agreement chooses a strictly positive level of rent-seeking. The more assets the party possesses the lower are the corresponding rent-seeking costs. Alternatively, it can choose a higher level of rent seeking at the same costs. Hence, the one-period gain of deviating from the relational agreement is clearly higher. Further, a higher rent makes it more profitable to deviate from the agreement, as the reward for outperforming the other party is higher.

Let us now come to the costs of deviating from the relational agreement in form of higher rent-seeking costs in future periods. If the relational contract is reneged on, the parties choose integration and total per-period rent-seeking 
costs are given by $C_{T}:=C\left(x_{1}^{I}\right)+C\left(x_{2}^{I}\right)+K\left(d_{1}^{I}\right)+K\left(d_{2}^{I}\right)$. As both parties have equal bargaining power, their per-period expected utility after a deviation from the relational agreement is given by $0.5\left(R-C_{T}\right)$. If the relational agreement is not reneged on, the respective expected utility is given by $0.5 R$. Hence, the costs of deviating from the relational agreement are given by $\frac{0.5 \delta C_{T}}{1-\delta}$. As well known from other models on relational contracting, these costs are increasing in $\delta$, as a higher $\delta$ implies a less heavy discounting of utility from future periods. Further, note that the costs do not depend on the initial allocation of the assets, i.e. the allocation of assets at the time the relational agreement was entered. Finally, we can relate $C_{T}$ and, accordingly, the costs of deviating from the agreement to the size of the rent, $R$. In this context, it can be shown that $C_{T}$ usually increases in $R$. More concretely, after an increase in $R$, the integrating party always increases its rent-seeking efforts, which, correspondingly, leads to higher costs. Whether the integrated party rent-seeks more, depends on two countervailing effects. First, there is a direct positive effect on rent seeking due to the higher rent. Second, there is an indirect effect, too, as the higher efforts of the integrating party discourage the integrated one and make it less attractive for the latter to engage in rent seeking. The direct effect is dominant and, hence, an increase in the rent certainly leads to higher costs of deviating from the relational agreement, if the cross derivatives $p_{12}$ and $p_{21}$ are not too large. Note, however, that, similar to the argumentation in connection with Proposition 1, this is a sufficient condition, which is oftentimes too strong. The next lemma summarizes these results.

Lemma 2 The costs of deviating from the relational agreement are independent of the number of assets each party possesses. Further, if the cross derivatives $p_{12}$ and $p_{21}$ are not too large, the costs are increasing in the size of the rent, $R$.

Proof. See Appendix A.

Comparing gains and costs of deviating from the relational contract, it 
is straightforward to derive the next proposition, which contains the main result of the paper.

Proposition 2 Denote by $\delta_{N}$ and $\delta_{I}$ the minimal discount factor under nonintegration and integration, respectively, for which a two-sided relational contract is feasible. Then, $\delta_{I}>\delta_{N}$. Hence, if $\delta \in\left[\delta_{N}, \delta_{I}\right)$, only non-integration makes two-sided relational contracts sustainable and is therefore preferred.

Proof. See Appendix A.

Proposition 2 demonstrates that a two-sided relational contract, under which both parties do not engage in rent seeking, is more difficult to sustain under integration than under non-integration. This represents an important downside to integration, which was not simply assumed, but derived endogenously. The reason is that the integrating party can choose a certain level of rent seeking at lower costs and, hence, is more tempted to deviate from the relational contract than any party under non-integration. This finding seems to map practice very well. To give an example, take a look at the Japanese automobile industry, which is famous for its comprehensive reliance on relational contracts. The industry has attracted many researchers and detailed descriptions of its functioning have been given. ${ }^{18}$ To connect these descriptions with our model, consider the following statements by Holmström \& Roberts (1998, p. 81, 82):

"The key to making [the Japanese] system work is obviously the longterm repeated nature of the interaction. Although supply contracts are nominally year-by-year, the shared understanding is that the chosen supplier will have the business until the model is redesigned, which lasts typically four or five years. Moreover, the expectation is that firms will continue to do business together indefinitely.[...] The familiar logic of repeated games, that future rewards and punishments motivate current behavior, supports the ongoing dealings. An attempted hold-up would presumably bring severe future

\footnotetext{
${ }^{18}$ See, for instance, Asanuma $(1989,1992)$, Taylor \& Wiggins (1997) or Holmström \& Roberts (1998).
} 
penalties.[...] Perhaps the major problem in the system may be that the automakers are inherently too powerful and thus face too great a temptation to misbehave opportunistically." (emphasis added)

The final statement can be understood as an informal description of our main result that a party, which possesses many assets and, hence, is relatively powerful may be tempted to renege on the relational contract. To sustain relational contracts in spite of the potential dominance of the automakers, our model would propose to make the situation more even. Note that this is exactly the case in the Japanese automobile industry. First, automakers oftentimes purchase their intermediate products from independent suppliers, i.e. suppliers owning their production facilities themselves, which means that they choose non-integration as the primary ownership structure. Second, suppliers are organized in a supplier association, which aims at further counterbalancing the initial power asymmetry.

As mentioned in the introduction, a main finding of the empirical literature on the theory of the firm is that integration is more likely to be chosen for higher values of the rent, $R$. To relate the model to this finding, recall that integration is optimal in the absence of relational contracts, but nonintegration is (maybe uniquely) optimal, if two-sided relational contracts are feasible. Thus, the model predictions are in line with the empirical facts, if the sustainability of two-sided relational contracts decreases in the size of the rent. In the (relatively) general model that we have presented, however, this cannot be shown. All we can say is that an increase in $R$ (usually) has two countervailing effects on the sustainability of relational contracts, as both, the one-period gain and the future costs of deviating from the relational agreement get higher. It is, however, easy to find examples for which the first effect is always dominant. Assume, for instance, that party $i$ is awarded the rent, if $y_{i}+\varepsilon_{i}>y_{j}+\varepsilon_{j}{ }^{19}$ where $\varepsilon_{i}$ is an error term being independently and uniformly distributed on the interval $[-a, a]$, with $a>0$. Further, let $C\left(x_{i}\right)=\frac{c}{2} x_{i}^{2}$ and $K\left(d_{i j}\right)=\frac{c}{2} d_{i j}^{2}$. Then, the first effect is always dominant and

\footnotetext{
${ }^{19}$ This decision "rule" is an example of a probit-form contest.
} 
the relational agreement becomes less stable, as the rent increases ${ }^{20}$, which fits very well to the empirical facts.

\section{Discussion}

\subsection{Different contest-success functions}

Up to this point, we have assumed that $p$ is everywhere differentiable. This is e.g. usually the case, if a probit-form contest is considered. In some applications, however, the contest-success function is supposed to have the following logit-form:

$$
p\left(y_{1}, y_{2}\right)=\left\{\begin{array}{c}
\frac{f_{1}\left(y_{1}\right)}{f_{1}\left(y_{1}\right)+f_{2}\left(y_{2}\right)}, \text { if } f_{1}\left(y_{1}\right)+f_{2}\left(y_{2}\right)>0 \\
0.5, \text { otherwise }
\end{array}\right.
$$

The functions $f_{1}(\cdot)$ and $f_{2}(\cdot)$ are increasing, concave and non-negative. If then $f_{1}(0)=f_{2}(0)=0, p$ is discontinuous and non-differentiable at $y_{1}=$ $y_{2}=0$ implying that $p(\epsilon, 0)=1$, for $\epsilon>0$ and $\epsilon \rightarrow 0$. In this case, the optimal deviation from a two-sided relational contract is to marginally raise total rent-seeking activities and capture the rent with probability one. Then, the one-period gain from deviating is independent of the ownership structure and given by $R$ so that the results in Lemma 1 and Proposition 2 no longer hold.

Nevertheless, even with a contest-success function of the form (17), there are possible and convincing modifications of the model, which extinct the problems due to a discontinuity of $p$ so that all derived results continue to hold. First, one could simply assume that $f_{1}(0), f_{2}(0)>0$, which is, as an ad-hoc assumption, not more restrictive than $f_{1}(0)=f_{2}(0)=0$. Second, one could assume $f_{1}(0)=f_{2}(0)=0$ and modify the assumption that party $i$ can observe, whether or not $y_{j}>0$. Instead, one could assume that it can observe, whether or not $y_{j}>\hat{y}$, with $\hat{y}>0$. That is, it can observe,

\footnotetext{
${ }^{20}$ Appendix B presents the example in a more detailed way and contains a formal proof of this statement.
} 
whether party $j$ engages moderately or heavily in rent-seeking, while we still do not need the rather unrealistic assumption that the exact level of $y_{j}$ is observable. If, then, $\hat{y}$ is not too large, we obtain the same results as in the model presented so far.

\subsection{One-sided relational contracts}

As mentioned in Section 3, a two-sided contract may not be the only form of relational agreement. The parties may also enter a one-sided relational contract, under which one party promises not to engage in rent seeking, but the other is allowed to do so. Under such a contract, the latter party (say party $i$ ) chooses its best response to $y_{j}=0$. Hence, the only party that might be interested in deviating from the agreement, is the party promising not to rent-seek.

There are different effects on the sustainability and profitability of onesided relational contracts. A complete formal treatment of these effects is beyond the scope of this paper. What we will do, however, is to provide an informal treatment, which is helpful in developing a deeper understanding of this kind of contract. Let us begin with the sustainability that is again determined by comparison of gains and costs of deviating from the relational agreement. Note first that the costs of deviating from the agreement still do not depend on the chosen ownership structure, as costless renegotiation of the ownership structure is assumed. The corresponding gain, on the other hand, is affected by the ownership structure through two channels. First, we have the same effect as in the previous section, namely that possessing more assets makes it less costly to choose a certain level of rent seeking so that the gain of deviating from the relational agreement increases. Second, we have an additional effect, as the opponent party engages in rent seeking and chooses its best-response to $y_{j}=0$. This effect depends on the ownership structure as follows: Suppose that the party promising not to engage in rent seeking transfers an asset to the other party. Then, the latter party increases its rent-seeking activities, as rent seeking becomes less costly for it. This 
decreases both, the former party's winning-probability in case of honoring and not honoring the relational contract and, thus, affects the gain of deviating from the agreement through the cross derivative $p_{i j}$. It may or may not enforce the first effect. Hence, in order to give general predictions about how the sustainability of one-sided relational contracts depends on the ownership structure, we have to impose further restrictions on $p_{i j}$. If this derivative is not too large, the first effect always dominates. Then, withdrawing an asset from the party promising not to engage in rent seeking makes the contract more easily sustainable. This implies that a one-sided relational contract is most easily sustainable under integration, if the integrated party promises not to engage in rent seeking. Furthermore, such a contract is more easily sustainable than a two-sided relational contract since the latter type of contract is most easily sustainable under non-integration. Hence, there are parameter constellations, for which one-sided relational contracts are sustainable, but two-sided contracts are not.

Concerning the profitability of one-sided relational contracts, it does not suffice to consider their sustainability. As one party engages in rent seeking, it must also be captured that the cost this rent seeking entails may differ between the single ownership structures. Unfortunately, there are two countervailing effects, both of which may be dominant ${ }^{21}$. First, the party's rent seeking increases, if it has access to more assets. On the other hand, possessing more assets makes rent seeking less costly so that the costs, entailed by rent-seeking, decrease. As either effect may be dominant, one cannot rank the ownership structures unambiguously. Nevertheless, one can show that one-sided relational contracts improve the situation compared to the setting in Section 2, where no relational agreements are feasible at all. This is intuitive. As one party does not engage in rent seeking, competition is extremely weak. Therefore, the other party chooses lower rent-seeking efforts (as compared to the setting in Section 2), too. Combined with the result

\footnotetext{
${ }^{21}$ Using the specific example already considered in Section 3.2, this is shown in Appendix
} B. 
that one-sided contracts may be the only form of relational agreement to be sustained, this points to the potential importance of this kind of contract.

\section{Concluding remarks}

This paper presents a formal rent-seeking theory of the firm. The main idea is that a transfer of an asset from one party to another makes rent seeking less costly for the new and more costly for the initial owner. Under this assumption, it can be shown that integration is optimal in the absence of relational contracts, for, in this case, integration makes the contest less even and, hence, less intense. Two-sided relational contracts, however, may only be sustainable under non-integration, in which case this ownership structure is optimal.

Several extensions of the model could be addressed. First, one could consider a setting with $n>2$ parties. In such a situation, similar results as in the two-party setting should be derived. If no relational contracts are feasible, all assets should be transferred to one party to make the contest uneven. Otherwise, it might be better to allocate the assets to more than one party.

Second, we could assume that the parties are heterogeneous in the sense that they have different haggling abilities. Here, in a situation without relational contracts, all assets should be allocated to the most able party in order to make the contest least intense. Different from our results, however, integration by the less able party may be the only ownership structure under which two-sided relational contracts are feasible. This ownership structure may make rent seeking equally costly for both parties (the more able party may have a cost advantage due to its ability, the other party due to possession of more assets) and so may limit the one-period gain of deviating from the relational contract of both parties.

Third, one could model relational contracts using a finite-horizon approach with parties of different types; honest parties, who always stick to 
their promises and dishonest ones, who stick to their promises only if this pays off for them. ${ }^{22}$ Such an approach may be beneficial, as it can explain changes in ownership structures over time. If a type of a party is revealed in the course of the game, it may be optimal to switch to another ownership structure. The current modeling approach cannot explain such changes, as, on the equilibrium path, the chosen ownership structure is always the same.

\section{Appendix A (Proof of Propositions 1, 2 and Lemmas 1, 2) :}

Proof of Proposition 1:

We prove Proposition 1 by demonstrating that $x_{1}^{I}, x_{2}^{I}<x^{N}$ and $d_{1}^{I}, d_{2}^{I}<$ $d^{N}$. Consider first the condition $x_{1}^{I}<x^{N}$. This condition is equivalent to $p_{1}\left(x_{1}^{I}+d_{1}^{I}+d_{2}^{I}, x_{2}^{I}\right)<p_{1}\left(y^{N}, y^{N}\right)$. Define $y_{1}^{I}:=x_{1}^{I}+d_{1}^{I}+d_{2}^{I}$ and $y_{2}^{I}:=x_{2}^{I}$. We introduce a case distinction. In the first case, $y_{1}^{I} \leq y^{N}$. Suppose, then, that $x_{1}^{I} \geq x^{N}$. As shown before, this implies $p_{1}\left(x_{1}^{I}+d_{1}^{I}+d_{2}^{I}, x_{2}^{I}\right) \geq p_{1}\left(y^{N}, y^{N}\right)$, from which it follows that $d_{1}^{I} \geq d^{N}$. This last condition together with $d_{2}^{I}>0$ contradicts the initial assumption $y_{1}^{I} \leq y^{N}$. Hence, with $y_{1}^{I} \leq y^{N}$, it must be that $x_{1}^{I}<x^{N}$.

In the second case, let $y_{1}^{I}>y^{N}$. Further, assume $y_{2}^{I}<y^{N}$. Then, $p\left(y_{1}^{I}, y_{2}^{I}\right)>0.5$. Moreover, the condition $p_{1}\left(y_{1}^{I}, y_{2}^{I}\right)<p_{1}\left(y^{N}, y^{N}\right)$ can be rewritten as $p_{1}\left(y^{N}+a, y^{N}-b\right)<p_{1}\left(y^{N}, y^{N}\right)$, with $a, b>0$. As $p_{11} \leq 0$ and $p_{12}>0$ for $p>0.5$, it follows that $p_{1}\left(y^{N}+a, y^{N}-b\right) \leq p_{1}\left(y^{N}, y^{N}-b\right)<$ $p_{1}\left(y^{N}, y^{N}\right)$ and hence, $x_{1}^{I}<x^{N}$, hold, if $y_{2}^{I}<y^{N}$.

It remains to show that $y_{1}^{I}>y^{N}$ and $y_{2}^{I} \geq y^{N}$ cannot simultaneously hold. $y_{2}^{I} \geq y^{N}$ implies that $-p_{2}\left(y_{1}^{I}, y_{2}^{I}\right)>-p_{2}\left(y^{N}, y^{N}\right) \Leftrightarrow p_{2}\left(y^{N}, y^{N}\right)>p_{2}\left(y_{1}^{I}, y_{2}^{I}\right)$. If $y_{1}^{I}>y^{N}$ and $y_{2}^{I} \geq y^{N}$, the last condition can be rewritten as $p_{2}\left(y^{N}, y^{N}\right)>$ $p_{2}\left(y^{N}+c, y^{N}+d\right)$, with $c>0$ and $d \geq 0$. If $c>d, p>0.5$. Then, $p_{2}\left(y^{N}+c, y^{N}+d\right) \geq p_{2}\left(y^{N}+c, y^{N}\right)>p_{2}\left(y^{N}, y^{N}\right)$ since $p_{22} \geq 0$ and $p_{21}>$ 0 , for $p>0.5$, which contradicts our initial assumption. Further, $c \leq d$ would require $y_{1}^{I} \leq y_{2}^{I}$. As $K^{\prime}(0)=0$, this would imply $-p_{2}\left(y_{1}^{I}, y_{2}^{I}\right)>p_{1}\left(y_{1}^{I}, y_{2}^{I}\right)$, or, using the symmetry of $p, p_{1}\left(y_{2}^{I}, y_{1}^{I}\right)>p_{1}\left(y_{1}^{I}, y_{2}^{I}\right)$. Note, however, that $p_{1}\left(y_{1}^{I}, y_{2}^{I}\right) \geq p_{1}\left(y_{2}^{I}, y_{2}^{I}\right) \geq p_{1}\left(y_{2}^{I}, y_{1}^{I}\right)$, where the first inequality follows from

\footnotetext{
${ }^{22}$ See for such a finite-horizon approach e.g. Hart \& Holmström (1987) or Gürtler (2006).
} 
$p_{11} \leq 0$ and the second from $p_{12}>0$ for $p>0.5$. This is a contradiction. It follows that $y_{1}^{I}>y_{2}^{I}$, which suffices to show that $x_{1}^{I}<x^{N}$. Analogously, one can show that $d_{1}^{I}, d_{2}^{I}<d^{N}$.

Finally, we have to show that $x_{2}^{I}<x^{N}$, which is equivalent to $-p_{2}\left(y_{1}^{I}, y_{2}^{I}\right)<$ $-p_{2}\left(y^{N}, y^{N}\right) \Leftrightarrow p_{1}\left(y_{2}^{I}, y_{1}^{I}\right)<p_{1}\left(y^{N}, y^{N}\right)$. The proof is by contradiction. We suppose that $x_{2}^{I} \geq x^{N}$, which is equivalent to $p_{1}\left(y_{2}^{I}, y_{1}^{I}\right) \geq p_{1}\left(y^{N}, y^{N}\right)$. Recall that $y_{1}^{I}>y_{2}^{I}$. Then, as shown before, it must be that $y_{2}^{I}<y^{N}$ (as $y_{1}^{I}>y^{N}$ and $y_{2}^{I} \geq y^{N}$ cannot simultaneously hold). Let us rewrite the condition $p_{1}\left(y_{2}^{I}, y_{1}^{I}\right) \geq p_{1}\left(y^{N}, y^{N}\right)$ as $p_{1}\left(y^{N}+e, y^{N}+f\right) \geq p_{1}\left(y^{N}, y^{N}\right)$, with $e<0$, $f \gtrless 0$ and $e<f$. Note that $p_{1}\left(y^{N}+e, y^{N}+f\right)<p_{1}\left(y^{N}+e, y^{N}+e\right)$. Moreover, $p_{1}\left(y^{N}+e, y^{N}+e\right) \geq p_{1}\left(y^{N}, y^{N}+e\right)<p_{1}\left(y^{N}, y^{N}\right)$. The term $p_{1}\left(y^{N}+e, y^{N}+e\right)-p_{1}\left(y^{N}, y^{N}+e\right)$ can be rewritten as $\int_{y^{N}}^{y^{N}+e} p_{11}\left(t, y^{N}+e\right) d t=$ $-\int_{y^{N}+e}^{y^{N}} p_{11}\left(t, y^{N}+e\right) d t$. Hence, if $-p_{11}$ becomes very small, $p_{1}\left(y^{N}+e, y^{N}+e\right)-$ $p_{1}\left(y^{N}, y^{N}+e\right)$ becomes small, too, so that $p_{1}\left(y^{N}+e, y^{N}+e\right) \leq p_{1}\left(y^{N}, y^{N}\right)$. It then follows that $p_{1}\left(y^{N}+e, y^{N}+f\right)<p_{1}\left(y^{N}, y^{N}\right)$, which contradicts the assumption $x_{2}^{I} \geq x^{N}$. Hence, it must be that $x_{2}^{I}<x^{N}$.

The proof in the case party 2 is the integrating party is totally analogous. The only difference is that $p_{22}$ (instead of $-p_{11}$ ) must be small enough. This completes the proof of Proposition 1.

\section{Proof of Lemma 1:}

To prove the first part of the lemma consider two situations: In the first, party 1 possesses only its inalienable asset. In the second, it additionally possesses the first alienable asset. Suppose that, in the first situation, party 1 chooses a certain level of rent-seeking, say $\hat{y}$, and suffers rent-seeking costs $\hat{C}$. Then, in the second situation, it can choose the level $\hat{y}+\epsilon$, with $\epsilon>0$ and $\epsilon \rightarrow 0$ at the same cost $\hat{C}$, as $K^{\prime}(0)=0$. However, as $p_{1}>0$, it is better off compared to the first situation. With a similar argumentation, one can show that a party possessing both alienable assets (in addition to its inalienable 
one) is better off than a party possessing only one alienable asset.

The second part is easily proved as well. Suppose that, initially, the rent is given by $R_{1}$. Denote party 1's optimal deviation in this case by $\tilde{y}$. The gain from this deviation is given by $\Delta p R_{1}-\tilde{C}$, where $\Delta p$ denotes the difference in winning-probabilities and $\tilde{C}$ the cost from choosing $\tilde{y}$. Now let the rent increase from $R_{1}$ to $R_{2}>R_{1}$. If the party still chose $\tilde{y}$, the gain from deviation would change to $\Delta p R_{2}-\tilde{C}>\Delta p R_{1}-\tilde{C}$. If it decides to choose $y \neq \tilde{y}$, this must make the party (weakly) better off. Hence, the gain from deviating must increase in $R$. This completes the proof of Lemma 1.

\section{Proof of Lemma 2:}

The first part of Lemma 2 is obvious and therefore omitted. Concerning the second part of the lemma, recall that the costs of deviating from the relational agreement are given by $\frac{0.5 \delta C_{T}}{1-\delta}$. Hence, these costs are certainly increasing in the size of the rent, if each of the outlays, $x_{1}^{I}, x_{2}^{I}, d_{1}^{I}$ and $d_{2}^{I}$, is increasing in $R$. We prove this for the special case, where $C(\cdot)=K(\cdot)$. The proof for the case $C(\cdot) \neq K(\cdot)$ is analogous, but extremely messy. Suppose that party 1 is the integrating party. Then, we have, with $C(\cdot)=K(\cdot)$, $x_{1}^{I}=d_{1}^{I}=d_{2}^{I}=: \hat{x}$ and the first-order conditions simplify to

$$
\begin{aligned}
p_{1}\left(3 \hat{x}, x_{2}^{I}\right) R-C^{\prime}(\hat{x}) & =0 \\
-p_{2}\left(3 \hat{x}, x_{2}^{I}\right) R-C^{\prime}\left(x_{2}^{I}\right) & =0
\end{aligned}
$$

Totally differentiating with respect to $R$ yields the following two conditions:

$$
\begin{array}{r}
p_{1}\left(3 \hat{x}, x_{2}^{I}\right)+R\left(3 p_{11}\left(3 \hat{x}, x_{2}^{I}\right) \frac{\partial \hat{x}}{\partial R}+p_{12}\left(3 \hat{x}, x_{2}^{I}\right) \frac{\partial x_{2}^{I}}{\partial R}\right)-C^{\prime \prime}(\hat{x}) \frac{\partial \hat{x}}{\partial R}=0 \\
-p_{2}\left(3 \hat{x}, x_{2}^{I}\right)-R\left(3 p_{21}\left(3 \hat{x}, x_{2}^{I}\right) \frac{\partial \hat{x}}{\partial R}+p_{22}\left(3 \hat{x}, x_{2}^{I}\right) \frac{\partial x_{2}^{I}}{\partial R}\right)-C^{\prime \prime}\left(x_{2}^{I}\right) \frac{\partial x_{2}^{I}}{\partial R}=0
\end{array}
$$

Transforming these equations yields

$$
\begin{aligned}
\frac{\partial \hat{x}}{\partial R} & =\frac{R p_{12}\left(3 \hat{x}, x_{2}^{I}\right) \frac{\partial x_{2}^{I}}{\partial R}+p_{1}\left(3 \hat{x}, x_{2}^{I}\right)}{-3 R p_{11}\left(3 \hat{x}, x_{2}^{I}\right)+C^{\prime \prime}(\hat{x})} \\
\frac{\partial x_{2}^{I}}{\partial R} & =\frac{-3 R p_{21}\left(3 \hat{x}, x_{2}^{I}\right) \frac{\partial \hat{x}}{\partial R}-p_{2}\left(3 \hat{x}, x_{2}^{I}\right)}{R p_{22}\left(3 \hat{x}, x_{2}^{I}\right)+C^{\prime \prime}\left(x_{2}^{I}\right)}
\end{aligned}
$$


Note that both denominators are strictly positive. Further, note that $p_{12}\left(3 \hat{x}, x_{2}^{I}\right)>$ 0 and $p_{21}\left(3 \hat{x}, x_{2}^{I}\right)>0$, as $p>0.5$. From the above condition, we see that $\frac{\partial \hat{x}}{\partial R} \leq 0$ can only hold if $\frac{\partial x_{2}^{I}}{\partial R}<0$. However, from the second condition, we see that $\frac{\partial x_{2}^{I}}{\partial R}<0$ can only hold, if $\frac{\partial \hat{x}}{\partial R}>0$. Hence, it must be that $\frac{\partial \hat{x}}{\partial R}>0$. Then, if $p_{21}$ is not too large, $\frac{\partial x_{2}^{I}}{\partial R}>0$, too, so that $C_{T}$ is strictly increasing in $R$. The case, where party 2 is the integrating party is totally analogous. This completes the proof of Lemma 2 .

Proof of Proposition 2:

The minimal discount factors are given by the following two conditions:

$$
\begin{aligned}
G^{N} & =\frac{0.5 \delta_{N} C_{T}}{1-\delta_{N}} \\
G^{I} & =\frac{0.5 \delta_{I} C_{T}}{1-\delta_{I}}
\end{aligned}
$$

Here, $G^{N}$ denotes the one-period gain from optimally deviating from the relational agreement under non-integration and $G^{I}$ the respective gain of the integrating party under integration. From Lemma 1, we know that $G^{I}>G^{N}$. It directly follows that $\delta_{I}>\delta_{N}$. Q.E.D. 


\section{Appendix B (Specific example):}

In this appendix, we consider a specific example. In this example, we first show that two-sided relational contracts become less easily sustainable, as the rent increases. Second, we show that either of the effects on the profitability of one-sided relational contracts may be dominant.

Suppose that party $i$ is awarded the rent, if $y_{i}+\varepsilon_{i}>y_{j}+\varepsilon_{j}$, where $\varepsilon_{i}$ is uniformly distributed on the interval [-a,a], with $a>0$. Further, let $C\left(x_{i}\right)=\frac{c}{2} x_{i}^{2}$ and $K\left(d_{i j}\right)=\frac{c}{2} d_{i j}^{2}$. Party 1's winning-probability is given by $\operatorname{Prob}\left\{y_{1}+\varepsilon_{1}>y_{2}+\varepsilon_{2}\right\}=: H\left(y_{1}-y_{2}\right)$, where $H(\cdot)$ is the distribution function of the composed random variable $\varepsilon_{2}-\varepsilon_{1}$ and $h(\cdot)$ the corresponding density function. As e.g. shown by Kräkel (2000), $H(\cdot)$ and $h(\cdot)$ are given by $^{23}$

$$
\begin{gathered}
H\left(y_{1}-y_{2}\right)=\left\{\begin{array}{c}
0, \text { if } y_{1}-y_{2}<-2 a \\
\frac{y_{1}-y_{2}}{2 a}+\frac{\left(y_{1}-y_{2}\right)^{2}}{8 a^{2}}+0.5, \text { if }-2 a \leq y_{1}-y_{2} \leq 0 \\
\frac{y_{1}-y_{2}}{2 a}-\frac{\left(y_{1}-y_{2}\right)^{2}}{8 a^{2}}+0.5, \text { if } 0<y_{1}-y_{2} \leq 2 a \\
1, \text { if } y_{1}-y_{2}>2 a
\end{array}\right. \\
h\left(y_{1}-y_{2}\right)=\left\{\begin{array}{c}
\frac{1}{2 a}+\frac{y_{1}-y_{2}}{4 a^{2}}, \text { if }-2 a \leq y_{1}-y_{2} \leq 0 \\
\frac{1}{2 a}-\frac{y_{1}-y_{2}}{4 a^{2}}, \text { if } 0 \leq y_{1}-y_{2} \leq 2 a \\
0, \text { otherwise }
\end{array}\right.
\end{gathered}
$$

Consider the static scenario and assume that party 2 was integrated by party 1. Then, it is easy to show that the parties' rent-seeking efforts $x_{1}^{I}, x_{2}^{I}, d_{1}^{I}$ and $d_{2}^{I}$ are all the same and given by the following first-order condition: ${ }^{24}$

$$
\left(\frac{1}{2 a}-\frac{2 x_{1}^{I}}{4 a^{2}}\right) R-c x_{1}^{I}=0 \Leftrightarrow x_{1}^{I}=\frac{a R}{2 a^{2} c+R}
$$

Total rent-seeking costs in the static scenario then equal $C_{T}=\frac{2 c a^{2} R^{2}}{\left(2 a^{2} c+R\right)^{2}}$.

\footnotetext{
${ }^{23}$ Note that $H(\cdot)$ is not differentiable at $-2 a, 0$ and $2 a$. However, this is unproblematic, as, in contrast to the contest-success functions from Section $4.1, H(\cdot)$ is continuous.

${ }^{24}$ We considered the interval $[0,2 a]$, when deriving the first-order conditions. Note that this was correct, as $2 x_{1}^{c}=\frac{2 a R}{2 a^{2} c+R}$ does indeed lie in $[0,2 a]$. Further, the second-order condition for party 1 is always fulfilled. For party 2, we need as a further restriction $R<4 c a^{2}$ to guarantee the fulfillment of the second-order condition.
} 
Let us now turn to the dynamic scenario. To begin, we consider the case of two-sided relational contracts and assume that the parties choose nonintegration (This assumption facilitates the analysis, but does not affect the results). The best deviation from a two-sided relational contract for party 1 is its best response to $y_{2}=0$. This best response is again symmetric and given by the same condition as the rent-seeking efforts in the static scenario under integration, namely $x_{1}^{d}=d_{1}^{d}=\frac{a R}{2 a^{2} c+R}$. We are now able to calculate the one-period gain from deviating, which equals

$$
\begin{aligned}
G^{N} & =R\left(\frac{2 x_{1}^{d}}{2 a}-\frac{\left(2 x_{1}^{d}\right)^{2}}{8 a^{2}}+0.5-0.5\right)-\frac{c a^{2} R^{2}}{\left(2 a^{2} c+R\right)^{2}} \\
& =R\left(\frac{2 R\left(2 a^{2} c+R\right)}{2\left(2 a^{2} c+R\right)^{2}}-\frac{R^{2}}{2\left(2 a^{2} c+R\right)^{2}}\right)-\frac{2 c a^{2} R^{2}}{2\left(2 a^{2} c+R\right)^{2}} \\
& =\frac{2 c a^{2} R^{2}+R^{3}}{2\left(2 a^{2} c+R\right)^{2}}
\end{aligned}
$$

This gain must be compared to the costs of deviation, which are given by

$$
\frac{0.5 \delta}{1-\delta} C_{T}=\frac{2 c a^{2} R^{2} \delta}{2\left(2 a^{2} c+R\right)^{2}(1-\delta)}
$$

Hence, party 1 will renege on the contract, if and only if

$$
\frac{2 c a^{2} R^{2}+R^{3}}{2\left(2 a^{2} c+R\right)^{2}}>\frac{2 c a^{2} R^{2} \delta}{2\left(2 a^{2} c+R\right)^{2}(1-\delta)} \Leftrightarrow R>2 c a^{2} \frac{2 \delta-1}{1-\delta}
$$

It can directly be seen that the reneging temptation increases and a two-sided relational contract becomes less easily sustainable, if $R$ gets higher.

Let us now briefly consider one-sided relational contracts. Suppose that party 1 is the party that is allowed to engage in rent seeking. This party's rent-seeking activities are again given by the best response to $y_{2}=0$. In analogy to the analysis of two-sided contracts, it can be shown that the solution is symmetric and given by $\hat{x}=\frac{2 a R}{4 a^{2} c+k R}$, where $k$ is either 1,2 or 3 depending on whether party 1 possesses no, one or two alienable assets. Total rent-seeking costs are then given by $\hat{C}_{T}=0.5 k c(\hat{x})^{2}=\frac{2 k c a^{2} R^{2}}{\left(4 a^{2} c+k R\right)^{2}}$. As $k$ increases from 1 to 2 or from 2 to 3 , these costs may either increase or 
decrease. Hence, each of the effects on the profitability of one-sided relational contracts may be dominant.

\section{References}

Anderson, E., Schmittlein, D., 1984, Integration of the sales force: an empirical examination. RAND Journal of Economics, 15, 385-395.

Asanuma, B., 1989, Manufacturer-Supplier Relationships in Japan and the Concept of Relation-Specific Skill. The Journal of the Japanese and International Economics, 3, 1-30.

Asanuma, B., 1992, Japanese Manufacturer-Supplier Relationships in International Perspective. In: Paul Sheard, ed., International Adjustment and the Japanese Economy. St. Leonards, Australia: Allen \& Unwin.

Baik, K.H., 1994, Effort Levels in Contests with Two Asymmetric Players. Southern Economic Journal, 61, 367-378.

Baker, G.P., Gibbons, R., Murphy, K.J., 2002, Relational Contracts and the Theory of the Firm. Quarterly Journal of Economics, 117, 39-84.

Baye, M.R., Hoppe, H.C., 2003, The Strategic Equivalence of Rent-Seeking, Innovation, and Patent-Race Games. Games and Economic Behavior, $44,217-226$.

Bolton, P., Dewatripont, M., 2005, Contract Theory, Cambridge, Massachusetts: The MIT Press.

Cyert, R., March, J., 1963, A behavioral theory of the firm. Englewood Cliffs, NJ: Prentice-Hall. Second edition, 1992. Oxford: Blackwell Publishers.

Dixit, A., 1987, Strategic Behavior in Contests. American Economic Review, 77, 891-898. 
Ellingsen, T., 1997, Efficiency Wages and X-Inefficiencies. Scandinavian Journal of Economics, 99, 581-596.

Garvey, G., 1995, Why Reputation Favors Joint Ventures over Vertical and Horizontal Integration: A Simple Model. Journal of Economic Behavior and Organization, 28, 387-397.

Gibbons, R., 2005, Four formal(izable) theories of the firm? Journal of Economic Behavior \& Organization, 58, 200-245.

Grossman, S., Hart, O., 1986, The Costs and Benefits of Ownership: A Theory of Vertical and Lateral Integration. Journal of Political Economy, 94, 691-719.

Gürtler, O., 2006, Implicit Contracts: Two Different Approaches. SFB/TR 15 Discussion Paper No. 110.

Halonen, M., 2002, Reputation and the Allocation of Ownership. The Economic Journal, 112, 539-558.

Hart, O., Holmström, B., 1987, The theory of contracts. In T.F. Bewley (ed.), Advances in Economic Theory, Cambridge: Cambridge University Press, 71-155.

Hart, O., Moore, J., 1990, Property Rights and the Nature of the Firm. Journal of Political Economy, 98, 1119-1158.

Holmström, B., Roberts, J., 1998, The Boundaries of the Firm Revisited. Journal of Economic Perspectives, 12, 73-94.

Inderst, R., Müller, H.M., Wärneryd, K., 2005, Influence Costs and Hierarchy. Economics of Governance, 6, 177-197.

Inderst, R., Müller, H.M., Wärneryd, K., 2006, Distributional Conflict in Organizations. European Economic Review, forthcoming. 
Joskow, P., 1985, Vertical integration and long-term contracts: the case of coal-burning electric generation plants. Journal of Law, Economics, and Organization, 1, 33-80.

Klein, B., Crawford, R., Alchian, A., 1978, Vertical integration, appropriable rents and the competitive contracting process. Journal of Law and Economics, 21, 297-326.

Konrad, K.A., 2000, Sabotage in Rent-Seeking Contests. Journal of Law, Economics and Organization, 16, 155-165.

Konrad, K.A., 2004, Bidding in Hierarchies. European Economic Review, 48, 1301-1308.

Kräkel, M., 2000, Relative deprivation in rank-order tournaments. Labour Economics, 7, 385-407.

Lazear, E.P., Rosen, S., 1981, Rank-order tournaments as optimum labor contracts. Journal of Political Economy, 89, 841-864.

Lee, S., 2000, Contests with Externalities. Seoul Journal of Economics, 13, 123-134.

Leininger, W., 1993, More efficient rent-seeking - A Münchhausen solution. Public Choice, 75, 43-62.

March, J., 1962, The business firm as a political coalition. Journal of Politics, 24, 662-678.

Masten, S., 1984, The organization of production: evidence from the Aerospace industry. Journal of Law and Economics, 27, 403-417.

Masten, S., 1986, Institutional Choice and the Organization of Production: The Make-or-Buy Decision. Journal of Institutional and Theoretical Economics, 142, 493-509. 
Monteverde, K., Teece, D., 1982, Supplier switching costs and vertical integration in the automobile industry. Bell Journal of Economics, 13, 206-212.

Morgan, J., 2003, Sequential contests. Public Choice, 116, 1-18.

Müller, H.M., Wärneryd, K., 2001, Inside versus Outside Ownership: A Political Theory of the Firm. RAND Journal of Economics, 32, 527541.

Pfeffer, J., 1981, Power in Organizations. Ballinger, Cambridge, MA.

Taylor, C.R., Wiggins, S.N., 1997, Competition or Compensation: Supplier Incentives Under the American and Japanese Subcontracting Systems. American Economic Review, 87, 598-618.

Tullock, G., 1980, Efficient rent-seeking. In J.M. Buchanan et al. (Eds.), Toward a theory of the rent-seeking society. College Station: Texas A\&M University Press.

Wärneryd, K., 2000, In Defense of Lawyers: Moral Hazard as an Aid to Cooperation. Games and Economic Behavior, 33, 145-158.

Williamson, O., 1971, The vertical integration of production: market failure considerations. American Economic Review, 61, 112-123.

Williamson, O., 1979, Transaction Cost economics: the governance of contractual relations. Journal of Law and Economics, 22, 233-261.

Williamson, O., 1985, The Economic Institutions of Capitalism. Free Press, New York, NY. 